\title{
Investigating potential biases in observed and modeled metrics of aerosol-cloud-precipitation interactions
}

\author{
H. T. Duong ${ }^{1}$, A. Sorooshian ${ }^{1,2}$, and G. Feingold ${ }^{3}$ \\ ${ }^{1}$ Department of Chemical and Environmental Engineering, University of Arizona, Tucson, Arizona 85721, USA \\ ${ }^{2}$ Department of Atmospheric Sciences, University of Arizona, Tucson, Arizona 85721, USA \\ ${ }^{3}$ NOAA Earth Systems Research Laboratory, Boulder, Colorado 80305, USA
}

Received: 29 October 2010 - Published in Atmos. Chem. Phys. Discuss.: 8 December 2010

Revised: 5 April 2011 - Accepted: 24 April 2011 - Published: 3 May 2011

\begin{abstract}
This study utilizes large eddy simulation, aircraft measurements, and satellite observations to identify factors that bias the absolute magnitude of metrics of aerosol-cloudprecipitation interactions for warm clouds. The metrics considered are precipitation susceptibility $S_{o}$, which examines rain rate sensitivity to changes in drop number, and a cloudprecipitation metric, $\chi$, which relates changes in rain rate to those in drop size. While wide ranges in rain rate exist at fixed cloud drop concentration for different cloud liquid water amounts, $\chi$ and $S_{o}$ are shown to be relatively insensitive to the growth phase of the cloud for large datasets that include data representing the full spectrum of cloud lifetime. Spatial resolution of measurements is shown to influence the liquid water path-dependent behavior of $S_{o}$ and $\chi$. Other factors of importance are the choice of the minimum rain rate threshold, and how to quantify rain rate, drop size, and the cloud condensation nucleus proxy. Finally, low biases in retrieved aerosol amounts owing to wet scavenging and high biases associated with above-cloud aerosol layers should be accounted for. The paper explores the impact of these effects for model, satellite, and aircraft data.
\end{abstract}

\section{Introduction}

The representation of the physical processes relating aerosol particles, clouds, and precipitation in general circulation models (GCMs) is characterized by highly uncertain parameterizations (Lohmann and Feichter, 2005). The links between aerosol, clouds, and rainfall remain poorly understood owing to the complexity of the processes, measurement limitations, and the difficulty in isolating aerosol effects from competing factors such as meteorology. Climate models employ spatial resolution $(>100 \mathrm{~km})$ that is far coarser than the tools used to inform parameterizations of aerosol-cloud processes, including cloud model simulations and observations. Even at the higher spatial resolutions available with these techniques, there exists large uncertainty in quantifying cloud responses to changes in aerosol owing to differences in measurement and data analysis techniques (McComiskey and Feingold, 2008; Grandey and Stier, 2010). It is therefore important to address the source of variability in reported values of aerosol-cloud-precipitation metrics, especially when comparing measurements between in situ measurements, models, and satellite remote sensors.

The various constructs that are examined in this work are of interest because they provide a link between climate model parameterizations and observational and modeling studies. For example, the process of collision-coalescence between cloud drops to form precipitation, termed autoconversion, is represented in GCMs using a parameterization typically relating rain rate $(R)$ to the amount of liquid water in clouds (i.e. liquid water path, LWP) and drop number concentration $\left(N_{\mathrm{d}}\right)$ in the form of the following power law:

$$
R \sim \operatorname{LWP}^{x_{1}} N_{\mathrm{d}}^{x_{2}}
$$

The connection between aerosol and $R$ is contained within the $x_{2}$ term since $N_{\mathrm{d}}$ is directly proportional to aerosol number concentration, $N_{\mathrm{a}}$. Values of $x_{2}$ range widely between -0.8 and -1.75 based on numerous aircraft-based studies in stratocumulus regions (Pawlowska and Brenguier, 2003; Comstock et al., 2004; van Zanten et al., 2005; Wood, 2005; $\mathrm{Lu}$ et al., 2009). Such a broad range leads to widely varying simulated strengths of the second aerosol indirect effect in climate models, some of which use $x_{2}$ values ranging between 0 and -1.79 (Quaas et al., 2009).

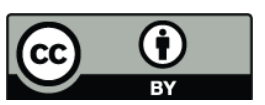

Correspondence to: A. Sorooshian

(armin@email.arizona.edu)

Published by Copernicus Publications on behalf of the European Geosciences Union. 
The following metrics have recently been introduced as a way to improve the quantification and understanding of aerosol-cloud-precipitation interactions (Feingold et al., 2001; Feingold and Siebert, 2009; Sorooshian et al., 2010):

$\mathrm{ACI}=-\frac{\partial \ln r_{e}}{\partial \ln \alpha}$

$\chi=\frac{\partial \ln R}{\partial \ln r_{e}}$

$S_{o}=-\frac{d \ln R}{d \ln N_{\mathrm{d}}}$

$S_{o}^{\prime}=-\frac{d \ln R}{d \ln \alpha}$

where $r_{\mathrm{e}}$ is drop effective radius, $\alpha$ is a cloud condensation nuclei $(\mathrm{CCN})$ proxy, and all partial derivatives are evaluated with macrophysical conditions (e.g. LWP) held fixed. ACI relates a change in drop size to an aerosol perturbation, and using basic assumptions, this term is bounded by the range $0-0.33$; a value of 0.33 corresponds to complete activation of sub-cloud aerosol into droplets (i.e. $\alpha=N_{\mathrm{d}}$ ). A wide range of ACI values has been reported in the literature, with higher values usually associated with in situ and ground-based measurements as compared to satellite remote sensing observations (McComiskey and Feingold, 2008); that study showed that a difference in ACI of 0.05 generates a large uncertainty in radiative forcing estimates $\left(\sim-7 \mathrm{~W} \mathrm{~m}^{-2}\right)$.

The relationship between aerosol perturbations and rain rate can be quantified as the precipitation susceptibility $\left(S_{o}\right)$, which relates the precipitation response to a change in drop concentration. Alternatively, $S_{o}$ can be indirectly obtained by the product of ACI and $\chi$ (Sorooshian et al., 2010). Using Eq. (4a), susceptibility can be quantified using remote retrievals of $N_{\mathrm{d}}$ (with assumptions; Bennartz 2007) without the need to assume that aerosol in cloud-free pixels is responsible for the microphysical response in adjacent cloudy pixels. On the other hand, Eq. (4b) can quantify susceptibility using the better-understood measurement of $\alpha$ (in the form of aerosol optical depth or aerosol index). Precipitation susceptibility is useful in that it comprises variables that can be observed and it is directly related to the previously-defined $x_{2}$ value in the autoconversion parameterization employed in climate models (at fixed LWP, $S_{o}=-x_{2}$ ).

A number of recent studies have shown similar qualitative behavior of $S_{o}$ as a function of LWP for shallow cumulus clouds (Jiang et al., 2010; Sorooshian et al., 2009a, 2010), where at low LWP, clouds are relatively insensitive to aerosol as they do not have a great potential to precipitate, while at larger LWP, clouds can precipitate more and they become progressively more sensitive to aerosol perturbations. The precipitation susceptibility of warm clouds grows with increasing LWP to a maximum, after which it decreases. This represents a shift from a precipitation regime dominated by autoconversion to one of accretion. Sorooshian et al. (2010) showed using modeling and observational data that $\chi$ essentially captures the essence of $S_{o}$ behavior as a function of LWP, while ACI is approximately invariant with LWP, provided data has been binned by LWP. However, these studies highlighted a number of issues, including statistical insignificance of the values of these metrics when calculated using satellite data $\left(S_{o}^{\prime}\right)$, and disagreement in both the absolute values of these metrics, and their LWP-dependent behavior amongst the various methods (in situ measurements, models, satellite remote sensing). Furthermore, aerosol-cloud-rain relationships such as precipitation susceptibility could potentially exhibit a different behavior for different cloud types such as shallow cumulus clouds and stratocumulus clouds (Wood et al., 2009).

The goal of this study is to directly identify potential sources of disagreement in ACI, $\chi, S_{o}$ between satellite observations, in situ observations, and large eddy simulation. We do so by examining the sensitivity of these parameters to a number of factors thought to bias their absolute magnitudes and LWP-dependent behavior. Only warm clouds are considered. The paper is structured as follows: (i) overview of experimental methods; (ii) analysis of the sensitivity of aerosolcloud-precipitation metrics to cloud lifetime and spatial resolution of measurements, method of quantifying aerosol-cloud parameters, using artificially low and high retrieved aerosol concentrations owing to wet scavenging and above-cloud aerosol layers, respectively; and (iii) conclusions.

\section{Experimental methods}

\subsection{Modeling}

The model used in this work is the Regional Atmospheric Modeling System (RAMS, version 6.0) (Cotton et al., 2003), a large eddy simulation (LES) model, coupled to an explicit bin-resolving microphysical model (Feingold et al., 1996; Stevens et al., 1996). The simulations are initialized with a thermodynamic sounding based on data from the Rain In Cumulus over Ocean (RICO) field experiment (Jiang et al., 2009, 2010); the model domain size is $25.6 \mathrm{~km} \times 25.6 \mathrm{~km} \times 6 \mathrm{~km}$ with a horizontal grid spacing of $100 \mathrm{~m}$ and vertical grid spacing of $\Delta z=40 \mathrm{~m}$ up to $4 \mathrm{~km}$, and vertically stretched above that height with a stretch factor of 1.035 .

Two simulations were carried out with initial aerosol concentrations $\left(N_{\mathrm{a}}\right)$ of $100 \mathrm{~cm}^{-3}$ and $300 \mathrm{~cm}^{-3}$ to represent clean and moderately polluted clouds, respectively. The simulations were run for $12 \mathrm{~h}$, but only output from hours 6 and 7 were examined. Individual clouds were manually tracked over the course of their lifetime, where a cloud is defined as having an average LWP exceeding $20 \mathrm{~g} \mathrm{~m}^{-2}$ and a minimum size of $0.3 \mathrm{~km} \times 0.3 \mathrm{~km}$. Merging and non-precipitating $(R<$ $0.5 \mathrm{~mm} \mathrm{day}^{-1}$ ) clouds are excluded in the analysis, to be consistent with the analysis of Jiang et al. (2010). Merging 
events are of great interest but significantly complicate the analysis because they provide the equivalent of a strong perturbation to the evolution of the microphysical and dynamical state of the individual clouds entering the merger. The cloud microphysical properties following a merging event change significantly as compared to the original clouds and therefore are not representative of the microphysical evolution of single clouds. For example, the maximum drop effective radius and precipitation rate of the newly merged clouds typically increase between a factor of two and four when compared to the original clouds prior to merging, predominantly owing to an acceleration in drop accretion. To avoid this complexity, we focus on the evolution of individual clouds. The analysis is restricted to clouds that exhibit lifetimes between $15-45 \mathrm{~min}$ ( $\sim 30 \%$ of clouds in each simulation), as these clouds reach sufficiently high LWP values to be classified as clouds and this discrimination also eliminated cases of merging clouds. Extensive details on lifetime and areal extent statistics for the entire cloud population are provided by Jiang et al. (2010; refer to their Fig. 4).

At each minute of a cloud's life the values of LWP, cloud-top drop effective radius $\left(r_{\mathrm{e}, \text { top }}\right)$, column-maximum drop effective radius $\left(r_{\mathrm{e}, \max }\right)$, column-maximum cloud drop concentration $\left(N_{\mathrm{d}, \max }\right)$, and column-maximum precipitation rate $\left(R_{\max }\right)$ are calculated. These values are then averaged over three different spatial resolutions $(0.3 \mathrm{~km} \times 0.3 \mathrm{~km}$, $0.5 \mathrm{~km} \times 0.5 \mathrm{~km}$, and $0.7 \mathrm{~km} \times 0.7 \mathrm{~km}$ ) at each sampling time. The highest resolution among these three resolutions $(0.3 \mathrm{~km} \times 0.3 \mathrm{~km})$ is centered around the maximum LWP, and extended outward for the lower resolutions. Note that some clouds were not sufficiently large to allow averages over the larger spatial areas. Clouds are categorized into three regimes based on terciles of lifetime: beginning ( 0 $33 \%$ lifetime), middle (33-67\% lifetime) and end (67$100 \%$ lifetime). ACI, $\chi$, and $S_{o}$ are quantified in each cloud lifetime category for 15 different LWP bins with midpoints including $50 \mathrm{~g} \mathrm{~m}^{-2}, 100 \mathrm{~g} \mathrm{~m}^{-2}$, and up to $1400 \mathrm{~g} \mathrm{~m}^{-2}$ in $100 \mathrm{~g} \mathrm{~m}^{-2}$ increments. LWP bins extend up to $10 \%$ around the midpoints (i.e. LWP $+10 \% \times$ LWP) to maintain similar numbers of points in each bin.

\subsection{Aircraft measurements}

The aircraft measurements derive from the second Marine Stratus/Stratocumulus Experiment (MASE-II) field campaign during July 2007 off the coast of Monterey, California. The objective of MASE-II was to study aerosolcloud interactions in stratocumulus clouds. The flights paths were designed to fly level legs below cloud base, at three levels in cloud (above-base, mid-level, below-top), and above cloud. Seven flights are examined here. The measurements and instrument payload are described extensively elsewhere (Hersey et al., 2009; Sorooshian et al., 2009b). Briefly, the forward scattering spectrometer probe (FSSP; PMS, modified by DMT Inc.) was used to quantify $N_{\mathrm{d}}$ and $r_{\mathrm{e}}$, while the cloud imaging probe (CIP), part of the cloud/aerosol/precipitation spectrometer package (CAPS; DMT Inc), was used to quantify drizzle rate $(R)$.

Maximum values for $N_{\mathrm{d}}, r_{\mathrm{e}}$, and $R$ were calculated as an average over a $2.5 \mathrm{~km}$ long stretch of a level leg with the maximum value of each parameter at the centerpoint; full level legs usually lasted $10-15 \mathrm{~min}(30-45 \mathrm{~km}$ at the aircraft speed $\sim 50 \mathrm{~m} \mathrm{~s}^{-1}$ ). Cloud-top and cloud-base values of various parameters were obtained by averaging data over the entire below-top and above-base legs, respectively. Data used in calculation of cloud parameters were only taken when LWC exceeded $0.05 \mathrm{~g} \mathrm{~m}^{-3}$ to avoid biased calculations when breaks appeared in the otherwise solid cloud. LWP is quantified as the vertical integration of the liquid water content (LWC) measured by a PVM-100 probe (Gerber et al., 1994) during slant ascents and descents through the cloud decks. Depending on the spatial variability in the cloud, these will deviate from true profiles. Column-integrated values of $r_{\mathrm{e}}$, $N_{\mathrm{d}}$, and $R$ are calculated using the slant ascent data as well. We assume that these data are representative of the profiles over a larger-scale cloud area defined by the level legs. The mean percentage difference for LWC, $r_{\mathrm{e}}, N_{\mathrm{d}}$, and $R$ values between level legs in cloud and at the same altitude during the selected slant ascent/descent are less than $20 \%$. A condensation particle counter (TSI CPC 3010, $D_{p}>10 \mathrm{~nm}$ ) and a passive cavity aerosol spectrometer probe (PCASP; PMS; $D_{p} \sim 100 \mathrm{~nm}$ to $2.6 \mu \mathrm{m}$ ) were used to quantify the sub-cloud aerosol number concentration $\left(N_{\mathrm{a}}\right)$.

\subsection{Satellite products}

For this study, 27 months of data are used from NASA's A Train constellation of satellites beginning from June 2006. The description of all satellite products and data filtering methodology are described extensively elsewhere (Lebsock et al., 2008; Sorooshian et al., 2010). Briefly, data are only used for warm maritime clouds in conditions of single cloud layers. Precipitation rate data are obtained from the CloudSat cloud profiling radar (CPR) (2C-PRECIP-COLUMN product; Haynes et al., 2009) within the range of $0.1-5 \mathrm{~mm} \mathrm{~h}^{-1}$. Collocated aerosol data are obtained from the Moderate Resolution Imaging Spectroradiometer (MODIS), specifically the $1^{\circ} \times 1^{\circ}$ gridded aerosol index (Level 3, MODIS Collection 5) (Remer et al., 2005), which is defined as the product of the $0.55 \mu \mathrm{m}$ aerosol optical depth $\times 0.55 / 0.867 \mu \mathrm{m}$ Ångstrom exponent. AI serves as a sub-cloud CCN proxy in the analysis as it has been shown to correlate better than AOD with columnar CCN concentrations (Nakajima et al., 2001; Bréon et al., 2002). Level 2 MODIS products at 1-km resolution are used to obtain data for cloud-top drop effective radius $\left(r_{\mathrm{e}}\right)$ and LWP (Platnick et al., 2003). In addition, atmospheric stability is quantified using estimates of the lower tropospheric static stability (LTSS) from the European Centre for Medium Range Weather Forecasts (ECMWF) analyses that have been matched to the CloudSat footprint (Partain, 
2007). LTSS $\left({ }^{\circ} \mathrm{C}\right)$ is defined as the potential temperature difference between $700 \mathrm{hPa}$ and $1000 \mathrm{hPa}$.

\section{Results and discussion}

Large eddy simulation output is used in Sects. 3.1 and 3.2 to examine the importance of cloud lifetime, spatial resolution, and the minimum $R$ threshold applied to the analysis. Aircraft measurements are used in Sect. 3.3 to discuss the choice of how to quantify aerosol-cloud properties. Satellite data are used in Sects. 3.4 and 3.5 to look at the effect of above-cloud aerosol layers and wet scavenging, respectively.

\subsection{Cloud lifetime}

Recent work has attempted to parameterize shallow cumulus $R$ in terms of $N_{\mathrm{d}}$ and LWP (Jiang et al., 2010). That work showed that the parameterization is significantly improved when cloud lifetime is taken into account. Building on those results, we quantify the sensitivity of $\chi$ and $S_{o}$ to cloud lifetime for shallow cumulus clouds using LES output. Modeling is used for this effort since satellites provide 'snapshots' at one point in time of a cloud field and therefore there is no direct measurement of what stage of a cloud the retrieved data represent. For example, is a cloud with a LWP of $800 \mathrm{~g} \mathrm{~m}^{-2}$ a budding cloud that is in a growing stage or a decaying cloud that is being depleted of its liquid water via precipitation?

To determine what effect cloud lifetime will have on $S_{o}$ and $\chi$, the dynamic ranges of $R$ and $r_{\mathrm{e}}$ are first evaluated at a representative LWP value $\left(800 \mathrm{~g} \mathrm{~m}^{-2}\right)$ for a population of clean and polluted clouds at all stages of their lifetime between $0-100 \%$ (Fig. 1). Note that few points are available at the beginning stages of clouds as they have not yet had sufficient time to reach a LWP of $800 \mathrm{~g} \mathrm{~m}^{-2}$. The two clusters of points at varying levels of $N_{\mathrm{d}}$ correspond to the "clean" and "polluted" simulations. Precipitation is driven more directly by droplet size rather than $N_{\mathrm{d}}$, which explains the narrower range in $R$ at fixed $r_{\mathrm{e}}$ as compared to fixed $N_{\mathrm{d}}$ (i.e. $R$ and $r_{\mathrm{e}}$ are more closely linked physically than $R$ and $N_{\mathrm{d}}$ ). Cloud lifetime is shown to be responsible for the wide range in $R$ at fixed $N_{\mathrm{d}}$, where clouds near the end of their lifetime are raining most heavily. The dynamic range in $R$ tends to be wider for the clean clouds versus more polluted clouds since they have a greater potential to rain owing to larger droplets at fixed LWP.

Figure 2 illustrates the effect of cloud lifetime on the values of $\chi$ and $S_{o}$ as a function of LWP when evaluated at different spatial resolutions. Consistent with previous work, $\chi$ and $S_{o}$ are non-monotonic functions of LWP and similarly exhibit small values at low LWP and then increase up to a threshold LWP value after which they decrease. At fixed spatial resolution, the absolute values and LWP-dependent behavior of $\chi$ and $S_{o}$ are insensitive to whether those val- ues were quantified at lifetimes of $0-33 \%, 33-67 \%, 67-$ $100 \%$, or $0-100 \%$. From Fig. 1, it is evident that the rare case when lifetime may have an important impact on $S_{o}$ is when using small datasets that only include clouds in clean and polluted conditions that were at opposite ends of cloud lifetime (clean + growing vs. polluted + decaying; clean + decaying vs. polluted + growing). $\chi$ will be less sensitive to lifetime as there is a relatively small dynamic range in $R$ at a given $r_{\mathrm{e}}$ as compared to fixed $N_{\mathrm{d}}$ conditions.

Remote sensing datasets typically include high volumes of data, so within a particular LWP bin it is expected that clouds across a wide range of lifetimes will be represented. Since the results for ACI (not shown), $\chi$, and $S_{o}$ are similar for clouds when analyzing data for various bins of cloud lifetime $(0-33 \%, 33-67 \%, 67-100 \%$, and $0-100 \%)$, this suggests that when using large datasets the absolute values of ACI, $\chi$, and $S_{o}$ will not be biased to a large extent. The effect of lifetime will likely become more important when using small datasets.

\subsection{Spatial resolution and minimum rain rate threshold}

The magnitude of aerosol-cloud relationships can be biased by the choice of the spatial resolution used for quantification of aerosol and cloud parameters (e.g. Grandey and Stier, 2010). This is partly due to varying aerosol types, cloud regimes, and meteorological conditions. The following analysis examines the sensitivity of the LWP-dependent behavior of aerosol-cloud constructs to three different LES spatial resolutions that are relatively fine as compared to satellitebased studies that often examine data at resolutions exceeding $1^{\circ} \times 1^{\circ}$. These finer spatial resolutions apply more to field measurements such as with aircraft.

As shown in Fig. 2, the peak values of $\chi$ and $S_{o}$ shift to lower LWP values with decreasing spatial resolution. This is thought to be because the mean LWP is reduced at lower resolution while values of $\chi$ and $S_{o}$ are preserved to a greater extent as they are quantified using relative magnitudes of $r_{\mathrm{e}}$, $R$, and $N_{\mathrm{d}}$. (Recall that the highest resolution is centered around the maximum cloud LWP and lower resolutions extend outward.) The values of $r_{\mathrm{e}}, R$, and $N_{\mathrm{d}}$ will undoubtedly vary if calculated over different spatial scales, however, the analysis here shows that their relationships to one another exhibit less sensitivity than the absolute value of LWP to the change in resolution. This effect of spatial resolution can at least partly explain results in recent studies (Jiang et al., 2010; Sorooshian et al., 2010) where the precipitation susceptibility of shallow cumulus clouds was shown to exhibit a maximum at varying LWPs, owing to averaging LWP across different spatial scales. Although not shown, at these relatively small scales, the ACI-LWP behavior is insensitive to resolution as ACI exhibits relatively stable values across the range of LWP examined, unlike $\chi$ and $S_{o}$ (Note that with LES output the value of ACI was quantified using $N_{\mathrm{d}}$ in place of $\alpha$ in denominator of Eq. 2). These results suggest that 

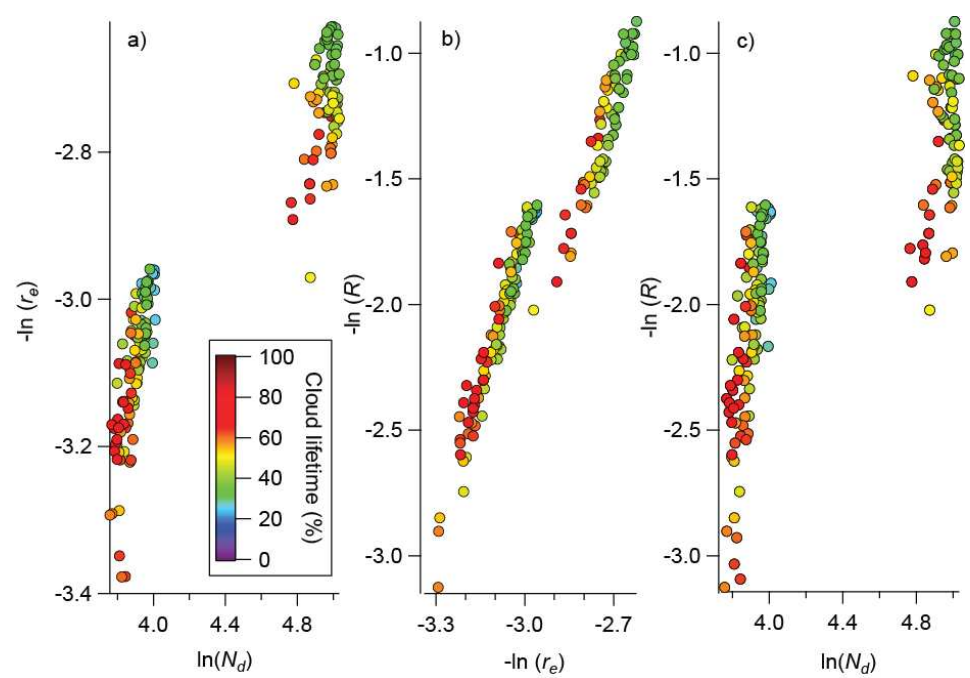

Fig. 1. Large eddy simulation analysis of the effect of cloud lifetime on the quantification of (a) $-\left.\frac{\partial \ln r_{e}}{\partial \ln N_{\mathrm{d}}}\right|_{\mathrm{LWP}}\left(=\mathrm{ACI}\right.$ with $N_{\mathrm{d}}$ in denominator), (b) $\chi$, and (c) $S_{o}$ for a representative LWP bin of $800 \mathrm{~g} \mathrm{~m}^{-2}$. The metric values are taken as slopes of the best fit lines. These data represent values quantified at a spatial resolution of $0.3 \times 0.3 \mathrm{~km}$ resolution.
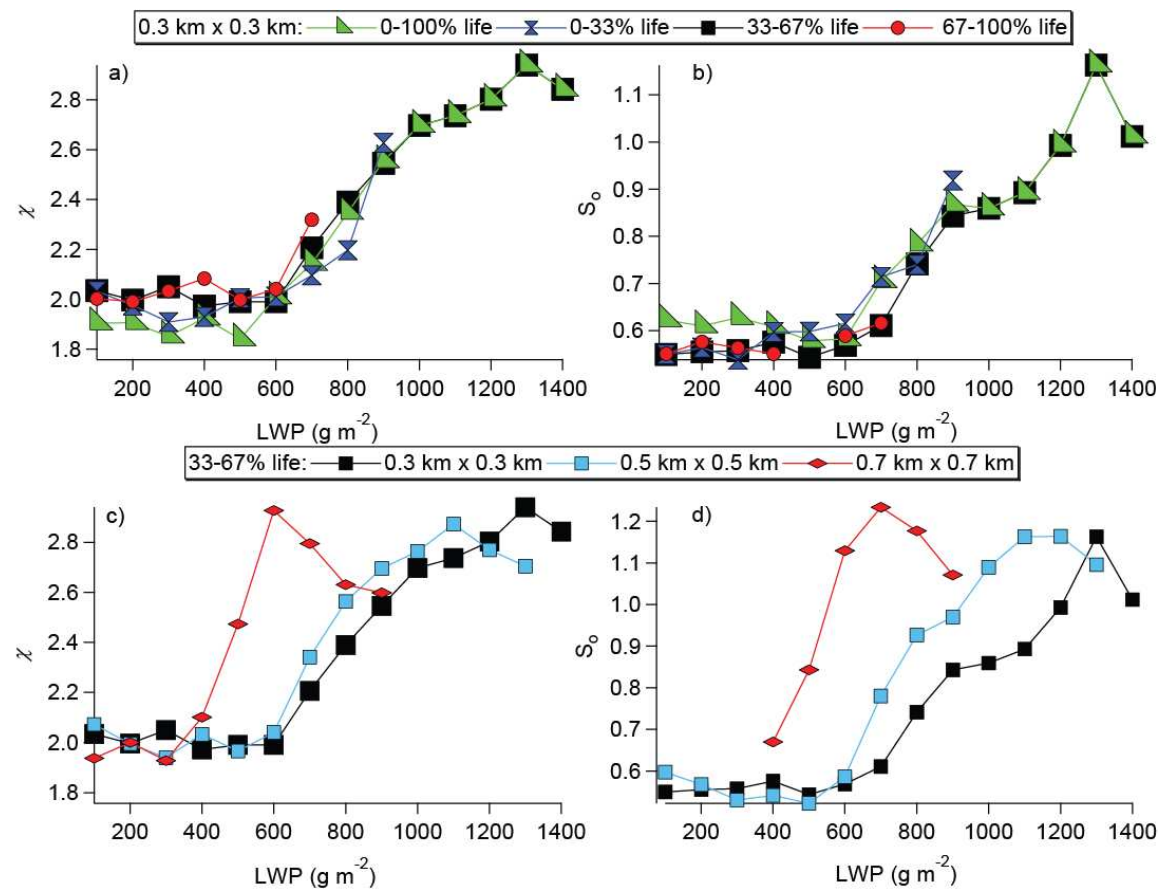

Fig. 2. Large eddy simulation analysis of the dependence of (a) $\chi$ and (b) $S_{o}$ on LWP and cloud lifetime, and also the dependence of (c) $\chi$ and (d) $S_{o}$ on LWP and spatial resolution over which data for aerosol and cloud properties were obtained from the LES output.

$\chi$ and $S_{o}$ will potentially exhibit peak values at lower LWP for datasets where LWP is often averaged over larger spatial scales such as with satellite observations.

An important note is that the choice of the minimum rain rate can alter the absolute value of $S_{o}$ and $\chi$ The analysis with LES data was limited to $R>0.5 \mathrm{~mm} \mathrm{~h}^{-1}$ and this discrimi- nation removes clouds with small drop effective radii that do not precipitate. Jiang et al. (2010) showed that lowering the $R$ threshold value from $0.5 \mathrm{~mm} \mathrm{day}^{-1}$ to $0.1 \mathrm{~mm} \mathrm{day}^{-1}$ results in a change in the absolute value of $x_{2}$ in Eq. (1) from -1.15 to -1.46 , which is equivalent to an increase in $S_{o}$ at fixed LWP. This is because the higher minimum 
Table 1. Aircraft measurement summary of the sensitivity of ACI, $\chi$, and $S_{o}$ (or $S_{o}^{\prime}$ ) to the choice of how the aerosol proxy $\left(N_{\mathrm{d}}\right.$ or $N_{\mathrm{a}}$ ), $R$, and $r_{\mathrm{e}}$ are quantified. The maximum values ("max") are quantified as being the average of the 25 points before/after the maximum value (corresponding to a level flight length of $\sim 2.5 \mathrm{~km}$ ). Column-integrated values ("col") represent the vertical integration of leg-mean values of the respective parameter. Cloud-top and base values ("top" and "base") represent the leg-mean value below cloud-top and above cloud base, respectively. $N_{\mathrm{a}}$ is the leg-mean average of particle concentration below cloud-base, as quantified with both a CPC $3010\left(D_{\mathrm{p}}>10 \mathrm{~nm}\right)$ and a PCASP $\left(D_{\mathrm{p}} \sim 100 \mathrm{~nm}-2.6 \mu \mathrm{m}\right)$. Bold signify that those points are not statistically significant with $95 \%$ confidence based on the student's t-test. Numbers in parentheses next to column and row headers correspond to the overall range of those values (Units: $N_{\mathrm{d}}$ and $N_{\mathrm{a}}=\# \mathrm{~cm}{ }^{-3}$; $r_{\mathrm{e}}=\mu \mathrm{m} ; R=\mathrm{mm}_{\text {day }}{ }^{-1}$ ).

\begin{tabular}{|c|c|c|c|c|c|c|c|}
\hline & $\begin{array}{c}N_{\mathrm{d}, \max } \\
(86-407)\end{array}$ & $\begin{array}{c}N_{\mathrm{d}, \mathrm{col}} \\
(47-229)\end{array}$ & $\begin{array}{c}N_{\mathrm{a}} \text { from } \\
\text { CPC } 3010 \\
(187-1360)\end{array}$ & $\begin{array}{c}N_{\mathrm{a}} \text { from } \\
\text { PCASP } \\
(54-424)\end{array}$ & $r_{\mathrm{e}, \max }$ & $r_{\mathrm{e}, \mathrm{col}}$ & $r_{\mathrm{e}, \mathrm{top}}$ \\
\hline \multicolumn{8}{|c|}{ ACI } \\
\hline$r_{\mathrm{e}, \max }(8.97-14.0)$ & 0.31 & 0.24 & 0.22 & 0.23 & & & \\
\hline$r_{\mathrm{e}, \mathrm{col}}(8.26-11.2)$ & 0.18 & 0.15 & 0.13 & 0.13 & & & \\
\hline$r_{\mathrm{e}, \mathrm{top}}(8.34-12.4)$ & 0.21 & 0.20 & 0.14 & 0.16 & & & \\
\hline & \multicolumn{2}{|c|}{$S_{o}$} & \multicolumn{2}{|c|}{$S_{o}^{\prime}$} & \multicolumn{3}{|c|}{$\chi$} \\
\hline$R_{\max }(0.75-8.19)$ & 1.23 & 1.10 & 0.88 & 0.90 & 4.24 & 4.16 & 4.20 \\
\hline$R_{\mathrm{col}}(0.5-1.60)$ & 0.37 & 0.44 & 0.19 & 0.25 & 1.31 & 0.78 & 0.93 \\
\hline$R_{\text {base }}(0.5-2.75)$ & 0.56 & 0.67 & 0.33 & 0.40 & 1.82 & 1.05 & 1.23 \\
\hline
\end{tabular}

$R$ threshold removes more low-precipitation data points for polluted clouds relative to clean clouds, thereby reducing the slopes used to calculate $S_{o}$ and $\chi$ (see Fig. 1). Therefore, the choice of the minimum $R$ threshold is important when comparing values of $S_{o}$ and $\chi$ between studies.

\section{Method of quantifying aerosol-cloud properties}

The analysis shown in Table 1 assesses the sensitivity of ACI, $\chi$, and, $S_{o}$ to the choice of how one quantifies the subcomponents of these metrics $\left(r_{\mathrm{e}}, N_{d}\right.$, and $R$ ) using aircraft measurements from the MASE II study. As an example of why this is important, the choice of whether to use cloud column-integrated values of $r_{\mathrm{e}}$ versus those at cloud-top has previously been shown to influence the value of ACI (Masunaga et al., 2002; Matsui et al., 2004, 2006). The choice of how to quantify each of these parameters to examine aerosolcloud interactions is dependent to a large extent on the intent of the analysis including the following: (i) meaningful intercomparisons with other aerosol-cloud datasets (e.g. other aircraft datasets, remote sensing data, and simulations such as LES); (ii) time synchronization with other measurements such as aerosol composition, size distributions, and hygroscopicity; and (iii) to directly improve climate model parameterizations that represent aerosol-cloud interactions at coarse spatial resolution.

Data from seven total cloud cases are examined exhibiting a LWP range between $31-55 \mathrm{~g} \mathrm{~m}^{-2}$ and an average subcloud $N_{\mathrm{a}}$ range between $180-1400 \mathrm{~cm}^{-3}$ (using CPC 3010). Cloud base drizzle rates during these cases ranged between
$0.5-2.7 \mathrm{~mm} \mathrm{day}^{-1}$. While the value of $r_{\mathrm{e}}$ is retrieved with satellite remote sensors at cloud-top, the aircraft data are used to quantify this parameter in multiple ways including at cloud-top, the maximum in-cloud value, and a columnintegrated average. The sub-cloud leg-mean $N_{\mathrm{a}}$ value is quantified using a CPC 3010 and a PCASP, while $N_{\mathrm{d}}$ is quantified as a maximum in-cloud value and a column-integrated in-cloud value. In addition to column-integrated and maximum values, $R$ is quantified here as the leg-mean value above cloud base.

Table, 1 shows that ACI values are smaller than $-\left.\frac{\partial \ln r_{e}}{\partial \ln N_{\mathrm{d}}}\right|_{\text {LWP }}$ (=ACI with $N_{\mathrm{d}}$ in denominator), with slight enhancements in ACI when using $N_{\mathrm{a}}$ values from the PCASP as compared to the CPC 3010. ACI values are expected to be lower than $-\left.\frac{\partial \ln r_{e}}{\partial \ln N_{\mathrm{d}}}\right|_{\text {LWP }}$, with a reduction approximately equal to the factor " $c$ ": $N_{\mathrm{d}} \sim N_{\mathrm{a}}^{c}$ (Feingold et al., 2001). The values of " $c$ " for these seven cases when using $N_{\mathrm{a}}$ (from CPC and PCASP) and $N_{\mathrm{d}, \max }$ are 0.62 and 0.67 , respectively, which are close to the ratios of ACI when calculated using $N_{\mathrm{a}}$ as the CCN proxy as compared to $N_{\mathrm{d} \text {,max }}(0.67-0.76)$. The $-\left.\frac{\partial \ln r_{e}}{\partial \ln N_{\mathrm{d}}}\right|_{\text {LWP }}$ values tend to approach 0.33 when using the $N_{\mathrm{d}}$ and $r_{\mathrm{e}}$ combinations that exhibit the widest range of values (value range: $N_{\mathrm{d}, \max }>N_{\mathrm{d} \text {, col }}$ and $r_{\mathrm{e}, \max }>r_{\mathrm{e}, \text { top }}>r_{\mathrm{e}, \mathrm{col}}$ ). Values of $\chi$ and $S_{o}$ (or $S_{o}^{\prime}$ ) are greater when using $R_{\max }$ versus either $R_{\text {base }}$ or $R_{\text {col }}$, where $R_{\max }$ exhibited a greater range of values. Values of the three aerosol-cloud constructs generally are more similar to each other when quantified using legaveraged and column-integrated values. The metric values and correlation coefficients are highest when quantifying the 
sub-components in ways that increase their dynamic range at least partly because the strength of the relationship between an aerosol perturbation and drop size (or $R$ ) at fixed LWP decreases over larger spatial scales. Furthermore, McComiskey et al. (2009) showed that ACI decreases over larger spatial domains because of the reduction in the correlative relationship between aerosol and cloud fields.

The intent of this analysis is not to propose that there be one generally accepted technique to calculate aerosol-cloud parameters, but to carefully consider these factors during intercomparisons between different studies. With regard to specific applications, it is worth noting that climate models benefit from the spatial coverage of satellite observations, which provide data at resolutions coarser than those represented by the "max" values used in Table 1. Therefore, the use of leg-averaged and column-integrated measurements of aerosol-cloud parameters better facilitate intercomparisons with satellite datasets. For purposes of intercomparison with remote sensing datasets, the choice of using either columnintegrated or leg-averaged aerosol parameters with aircraft data will often depend on how such values are quantified with the remote sensor of choice (e.g. cloud-top or columnintegrated data). Aircraft data obtained at finer resolution allow for more direct intercomparisons with cloud models with comparably high resolution such as LES.

It is also worth noting that the product of $\mathrm{ACI}$ and $\chi$ agrees with the directly-quantified $S_{o}$; for example, the product of $\chi$ (using $r_{\mathrm{e}, \max }$ and the various rain rates) with 0.31 (= ACI with $r_{\mathrm{e}, \max }$ and $\left.N_{\mathrm{d}, \max }\right)$ agrees to within $9 \%$ for all three combinations. This provides additional support for the utility of the deconstruction of the $S_{o}$ metric into sub-components (Sorooshian et al., 2010) to improve confidence in causal relationships between aerosol perturbations and the precipitation response of warm clouds by quantifying an intermediate step with the use of $r_{\mathrm{e}}$ (or alternatively cloud optical depth). Past work has also highlighted the significance of the relationship between drop effective radius and precipitation (e.g. Rosenfeld and Gutman, 1994).

\subsection{Above-cloud aerosol layers}

Previous work attempted to identify warm oceanic regions between a latitude range of $+/-30^{\circ}$ with the largest $S_{o}$ (Sorooshian et al., 2009a) and the largest potential relative reductions in $R$. It was shown that the greatest predicted relative reduction in warm rainfall is off the western coast of Africa. In that work, $\Delta R$ was calculated as the product of annual average of daily $S_{o}$ values (as determined by satelliteretrieved LWP and the $S_{o}$-LWP relationship from LES output for warm clouds) and $\mathrm{d} \ln (\mathrm{AI})$, as calculated from the dispersion (standard deviation/mean) in aerosol index for 2007. However, the assumption that a column-integrated value of $\mathrm{AI}$ is representative of aerosol impacting a cloud is especially problematic in conditions characterized by high above-cloud aerosol concentrations. In these conditions, AI becomes a poor proxy for sub-cloud CCN. Such aerosol plumes, which are common during the biomass burning season off the west coast of Africa, are clearly evident based on CALIPSO observations (e.g. Chand et al., 2009).

A closer examination of this region off the coast of Africa is carried out to assess the sensitivity of ACI, $\chi$, and $S_{o}^{\prime}$ to using satellite-retrieved aerosol in conditions when relatively high concentrations of aerosol reside above the cloud, to represent the sub-cloud $\mathrm{CCN}$ concentration. The spatial domain of this case study is $\left(5^{\circ} \mathrm{N}, 20^{\circ} \mathrm{S} ; 5^{\circ} \mathrm{E}, 35^{\circ} \mathrm{W}\right)$ and the time duration is between June and October of 2006. CALIPSO is used to identify cases of above-cloud aerosol plumes during all A-Train overpasses when warm rain was evident based on CloudSat observations. MODIS aerosol data were then filtered to avoid any $1^{\circ} \times 1^{\circ}$ scenes containing the abovecloud aerosol plumes. The analysis of ACI, $\chi$, and $S_{o}^{\prime}$ was subsequently carried out both with all of the data and with the filtered data. The analysis is conducted for 11 LWP bins with up to $10 \%$ spacing around bin midpoints, which increase in $25 \mathrm{~g} \mathrm{~m}^{-2}$ increments from 50 to $300 \mathrm{~g} \mathrm{~m}^{-2}$. The clouds in this region typically exhibit LTSS values in excess of $20^{\circ} \mathrm{C}$, which is indicative of stratocumulus clouds. Caution was taken to use CloudSat data beginning vertically in the lowest clutter-free range gate above the surface, which is between 600 and $840 \mathrm{~m}$ (Haynes et al., 2009).

Figure $3 \mathrm{a}$ shows that filtering the above-cloud plume data results in an enhancement in the majority of ACI and $S_{o}^{\prime}$ points, which rely on the collocated aerosol data retrieved by MODIS. On average, the enhancement in ACI and $S_{o}^{\prime}$ was $20 \%$ and $156 \%$, respectively, for the LWP range examined. The explanation for the depression of these values during cases of above-cloud plumes likely stems from a cluster of data points at very high aerosol concentrations that obfuscate the desired ACI and $S_{o}^{\prime}$ signals (hypothetically illustrated in Fig. 4), leading to a reduction in their absolute values. These results are in agreement with the recent work of Costantino and Bréon (2010), who examined the relationship between $\mathrm{AI}$ and $r_{\mathrm{e}}$ off the coast of Africa for cases when aerosols were in contact with clouds and when aerosols were clearly separated from cloud layers. They only detected a clear inverse relationship between AI and $r_{\mathrm{e}}$ for the former case. Abovecloud aerosol layers present a factor that may lead to lower values of ACI and $S_{o}^{\prime}$ as compared to surface and aircraft measurements and cloud models that are immune to this issue. The values of $\chi$ tend to be more evenly scattered about the 1:1 line, which is partly expected as $\chi$ does not rely on collocated aerosol data and thus is less sensitive to abovecloud plumes. On average, there was an $8 \%$ enhancement in $\chi$ after the data filtering.

An issue that cannot be ignored in this discussion is the effect of overlaying aerosol layers on MODIS retrievals of cloud properties such as $r_{\mathrm{e}}$ and LWP, which are typically thought to be biased low (e.g. Haywood et al., 2004; Cattani et al., 2006; Bennartz and Harshvardhan, 2007; Wilcox et al., 2009; Coddington et al., 2010). In support of the 

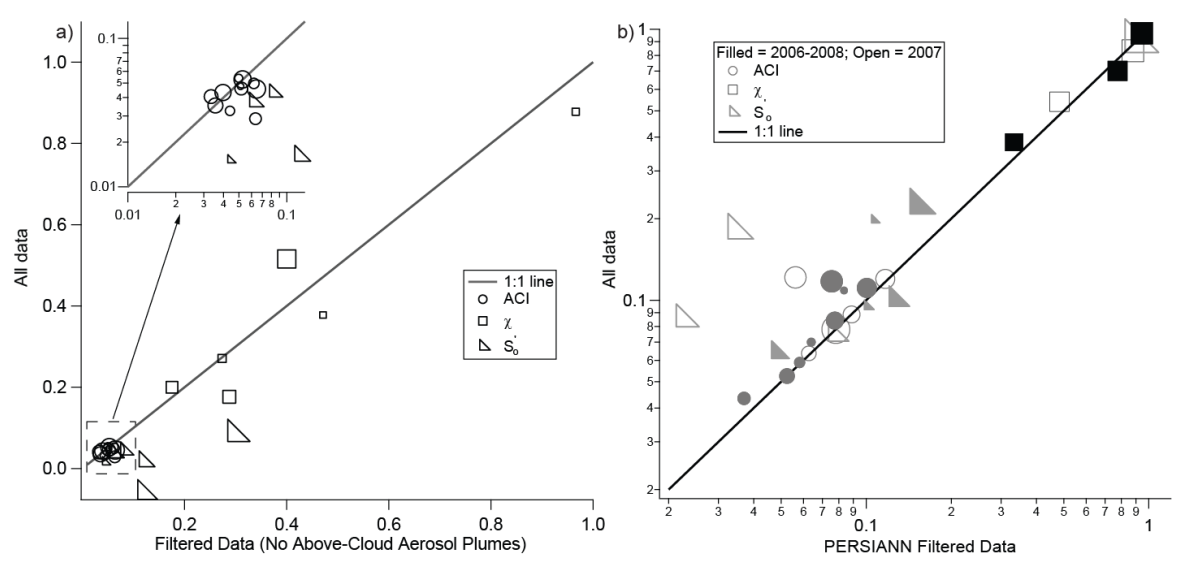

Fig. 3. Satellite data analysis of the sensitivity of aerosol-cloud-rain metrics to above-cloud aerosol plumes and wet scavenging. (a) Comparison of ACI, $\chi$, and $S_{o}^{\prime}$ with and without above-cloud aerosol plumes off the coast of western Africa. The data represent the time period between June and October 2006. Marker sizes are proportional to LWP [11 LWP bins with up to $10 \%$ spacing around bin midpoints (LWP \pm $10 \% \times \mathrm{LWP}$ ), which increase in $25 \mathrm{~g} \mathrm{~m}^{-2}$ increments from 50 to $300 \mathrm{~g} \mathrm{~m}^{-2}$ ]. (b) Comparison of ACI, $\chi$, and $S_{o}^{\prime}$ with and without filtering of wet scavenging events prior to A-Train overpasses within the same $1^{\circ} \times 1^{\circ}$ pixel. Marker sizes are proportional to LWP (12 LWP bins with up to $10 \%$ spacing around bin midpoints, which include $50 \mathrm{~g} \mathrm{~m}^{-2}, 100 \mathrm{~g} \mathrm{~m}^{-2}$, and up to $1100 \mathrm{~g} \mathrm{~m}^{-2}$ in $100 \mathrm{~g} \mathrm{~m}^{-2}$ increments). The data represent the JJA months for the three year period including 2006-2008 (filled) and 2007 only (open). Only points are reported in both panels that were statistically significant at $95 \%$ confidence (based on student's t-test) with and without the data filtering.

presented analysis, potential biases in $r_{\mathrm{e}}$ have been shown to be less than $1 \mu \mathrm{m}$ for retrievals where the visible reflectance is matched with the $3.7 \mu \mathrm{m}$ or $2.13 \mu \mathrm{m}$ reflectance. Wilcox et al. (2009) report that when the aerosol index obtained from the Ozone Monitoring Instrument (OMI) exceeds two, the estimated bias in the average LWP difference between AMSR$\mathrm{E}$ and MODIS exceeds the instantaneous uncertainty in the retrievals. Even after removing the data points in this case study analysis that exceeded this OMI threshold value (to account for issues in LWP retrievals), the conclusions of this analysis remain robust.

\subsection{Wet scavenging effects}

Artificially low aerosol concentrations resulting from wet scavenging can also influence the values of ACI, $\chi$, and $S_{o}^{\prime}$. The methodology in a number of studies has included obtaining data for rain and cloud properties from CloudSat and MODIS with a spatial resolution on the order of $1 \mathrm{~km}$, while aerosol data are retrieved from a significantly larger spatial domain $\left(1^{\circ} \times 1^{\circ}\right)$ (Lebsock et al., 2008; Sorooshian et al., 2009a, 2010). The effect of wet scavenging is tested using data for the months of June through August (JJA) between 2006-2008 and just the year 2007 within the tropics for shallow cumulus clouds. The Precipitation Estimation from Remotely Sensed Information using Artificial Neural Networks (PERSIANN; Sorooshian et al., 2000) product is used to remove cases of precipitation for a period of time up to a day before a satellite overpass within the same $1^{\circ} \times 1^{\circ}$ domain of MODIS aerosol retrievals. PERSIANN estimates rainfall using geostationary infrared imagery of clouds (e.g. GOES-
8, GOES-9/10, GMS-5, Metsat-6/7) and microwave instantaneous rainfall estimates (e.g. TRMM TMI). The analysis is performed for 12 LWP bins with up to $10 \%$ spacing around bin midpoints, which include $50 \mathrm{~g} \mathrm{~m}^{-2}, 100 \mathrm{~g} \mathrm{~m}^{-2}$, and up to $1100 \mathrm{~g} \mathrm{~m}^{-2}$ in $100 \mathrm{~g} \mathrm{~m}^{-2}$ increments. Approximately 20 $40 \%$ of the points were removed in each LWP bin when accounting for the wet scavenging effect.

Figure $3 \mathrm{~b}$ shows that $\mathrm{ACI}$ and $S_{o}^{\prime}$ values are scattered around the 1:1 line but with many points depressed after the PERSIANN filtering. The reduction in ACI and $S_{o}^{\prime}$ as a result of the data filtering is likely due to aerosol measurements being biased low when wet scavenging is not taken into account. Because wet scavenging could potentially influence the polluted scenes more than clean ones (because there is a greater potential to remove more aerosol; hypothetically illustrated in Fig. 4), larger aerosol values need to be shifted to commensurately larger values, which for the same cloud microphysical parameter results in weaker $\mathrm{ACI} / S_{o}^{\prime}$ slopes. Similar to the analysis of artificially high aerosol levels in Sect. 3.4, the value of $\chi$ is less sensitive to the wet scavenging data filtering because it does not require aerosol data in its quantification.

\section{Conclusions}

In previous work we explored the use of various parameters (ACI, $\chi$, and $S_{o}$, defined in Sect. 1) that attempt to quantify aerosol-cloud-precipitation processes, and here we assess the sensitivity of such metrics to numerous biasing factors using 


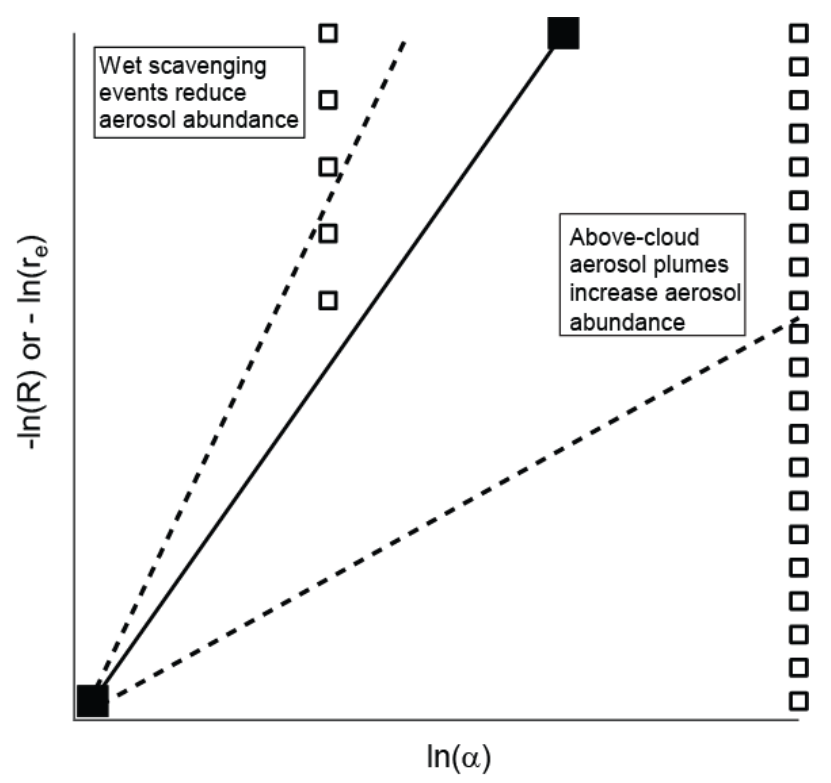

Fig. 4. A visual description of the effect that high and low aerosol concentrations could potentially have on quantification of ACI and $S_{o}^{\prime}$ when using collocated aerosol-cloud satellite data. The thick solid line represents a hypothetical slope when plotting $-\ln (R)$ or $\ln \left(r_{\mathrm{e}}\right)$ versus $\ln (\alpha)$, which corresponds to $S_{o}^{\prime}$ and ACI, respectively. With above-cloud aerosol plumes, a cluster of points at high levels of $\ln (\alpha)$ will reduce the slope (i.e. lower ACI and $S_{o}^{\prime}$ ). Low aerosol concentrations as a result of wet scavenging likely will have a greater impact for the most polluted scenes where there is a greater potential to have a reduction in aerosol concentration. This will lead to a higher slope (i.e. higher ACI and $S_{o}^{\prime}$ ). The $\chi$ metric is relatively insensitive to these effects as it avoids the use of retrieved aerosol data.

LES, satellite observations, and aircraft measurements. The major results of this work are as follows:

1. The time at which a cloud is sampled, relative to the overall cloud lifetime, could bias estimates of precipitation susceptibility because of the inherent timescale for a cloud to produce rainfall. This potential bias was examined for simulated shallow cumulus clouds. The absolute values of $\chi$ and $S_{o}$ are insensitive to whether those values were quantified at the beginning, middle, or end of cloud lifetime, unless sampling conditions were to somehow be biased towards covariance between magnitude of the aerosol perturbation, and stage of cloud development. Such covariance would be unlikely to exist in nature, except perhaps in small datasets. In large datasets, such as those from satellites, the effects of lifetime will likely be small owing to averaging amongst vast amounts of data representing clouds at varying stages in their lifetime, at their instantaneously measured LWP.
2. The choice and/or limitation of spatial resolution in observational datasets are shown to influence the LWPdependent behavior of $\chi$ and $S_{o}$. At low spatial resolution, the curves are compressed towards lower LWP (see Fig. 2); in other words, the point at which the maximum values of $\chi$ and $S_{o}$ are reached occur at lower LWPs. ACI is shown to be relatively constant as a function of LWP (provided ACI has been calculated in relatively narrow LWP bins) and therefore is not as dependent on spatial resolution as $\chi$ and $S_{o}$. Using higher minimum $R$ thresholds can underestimate $S_{o}$ and $\chi$ by removing more data points for polluted clouds that may precipitate more weakly than less polluted clouds.

3. The absolute magnitudes of $S_{o}, \chi$, and ACI are sensitive to the choice of how to quantify the aerosol proxy, $r_{\mathrm{e}}$, and $R$ (e.g. cloud-top, maximum, vertically-integrated), and to temporal/spatial averaging. Analyses of aircraft data of aerosol-stratocumulus interactions show that the values and correlative strengths of $S_{o}, \chi$, and ACI are reduced when using values of $N_{\mathrm{d}}, r_{\mathrm{e}}$, and $R$ that exhibit the lowest dynamic ranges over the span of clouds examined. This is most relevant to model and aircraftbased studies, where there are many choices for how to quantify these variable values, as opposed to satellitebased data sets where data products are more limited.

4. The inclusion of cases characterized by above-cloud aerosol plumes, as examined in a case study off the coast of western Africa, is shown to depress values of ACI and $S_{o}^{\prime}$. This is explained by data points at very high aerosol concentrations that obfuscate the desired ACI and $S_{o}^{\prime}$ signals. Appropriate filtering of these instances shows more realistic sensitivity. On the other hand, accounting for low biases in retrieved aerosol amounts as a result of wet scavenging with the use of an artificial neural network algorithm is shown in some cases to result in lower values of ACI and $S_{o}^{\prime}$. An explanation is that wet scavenging tends to influence the polluted scenes more than clean ones, resulting in greater reductions in aerosol abundance during cases with the lowest rain rates and drop sizes. The value of $\chi$ is relatively insensitive to both factors as it does not rely on collocated aerosol data, but only data within cloudy pixels.

While variations are expected in the values of the aerosolcloud-rain constructs examined here owing to the complexity of these physical interactions and meteorological feedbacks, it is necessary to understand how much of the variability is due to differences in measurement/modeling methodologies and data analysis techniques. Even though choices used in data analysis procedures will often be motivated by the specific application of the results (e.g. meaningful intercomparisons with other datasets, improving global climate models), the results of this study emphasize the importance 
of considering all the issues identified above when comparing results with other independent studies examining aerosolcloud interactions. For instance, details as basic as how, and at what resolution cloud microphysical parameters are calculated may have a major impact on the absolute value of the precipitation susceptibility of clouds to aerosol particles. Of the various parameters relating aerosols to rain in this work, $\chi$ is shown to be the least sensitive to the biasing factors investigated as it does not require collocated aerosol data in its calculation, which is especially advantageous for satellite studies.

Acknowledgements. This work was funded by an Office of Naval Research YIP Award (N00014-10-1-0811). The aircraft measurements were supported by the Office of Naval Research grant N00014-04-1-0018. G. F. acknowledges support from NOAA's Climate Goal.

Edited by: R. Cohen

\section{References}

Bennartz, R.: Global assessment of marine boundary layer cloud droplet number concentration from satellite, J. Geophys. Res., 112, D02201, doi:10.1029/2006JD007547, 2007.

Bennartz, R. and Harshvardhan: Correction to "Global assessment of marine boundary layer cloud droplet number concentration from satellite", J. Geophys. Res., 112, D16302, doi:10.1029/2007JD008841, 2007.

Bréon, F. M., Tanre, D., and Generoso, S.: Aerosol effect on cloud droplet size monitored from satellite, Science, 295(5556), 834838, 2002.

Cattani, E., Costa, M. J., Torricella, F., Levizzani, V., and Silva, A. M.: Influence of aerosol particles from biomass burning on cloud microphysical properties and radiative forcing, Atmos. Res., 82, 310-327, 2006.

Chand, D., Wood, R., Anderson, T., Satheesh, S. K., and Charlson, R. J.: Satellite-derived direct radiative effect of aerosols dependent on cloud cover, Nature Geosci., 2, 181-184, 2009.

Coddington, O. M., Pilewskie, P., Redemann, J., Platnick, S., Russell, P. B., Schmidt, K. S., Gore, W. J., Livingston, J., Wind, G., and Vukicevic, T.: Examining the impact of overlying aerosols on the retrieval of cloud optical properties from passive remote sensing, J. Geophys. Res., 115, D10211, doi:10.1029/2009JD012829, 2010.

Comstock, K. K., Wood, R., Yuter, S. E., and Bretherton, C. S.: Reflectivity and rain rate in and below drizzling stratocumulus, Quart. J. Roy. Meteor. Soc., 130, 2891-2918, 2004.

Costantino, L. and Bréon, F. M.: Analysis of aerosol-cloud interaction from multi-sensor satellite observations, Geophys. Res. Lett., 37, L11801, doi:10.1029/2009GL041828, 2010.

Cotton, W. R., Pielke, R. A., Walko, R. L., Liston, G. E., Tremback, C. J., Jiang, H., McAnelly, R. L., Harrington, J. Y., Nicholls, M. E., Carrio, G. G., and McFadden, J. P.: RAMS 2001: Current status and future directions, Meteorol. Atmos. Phys., 82(1-4), 5-29, 2003.
Feingold, G., Kreidenweis, S. M., Stevens, B., and Cotton, W.R.: Numerical simulations of stratocumulus processing of cloud condensation nuclei through collision-coalescence, J. Geophys. Res., 101, D16, 21391-21402, 1996.

Feingold, G., Remer, L. A., Ramaprasad, J., and Kaufman, Y. J.: Analysis of smoke impact on clouds in Brazilian biomass burning regions: An extension of Twomey's approach, J. Geophys. Res., 106, 22907-22922, 2001.

Feingold, G. and Siebert, H.: In Clouds in the Perturbed Climate System: Their Relationship to Energy Balance, Atmospheric Dynamics, and Precipitation, edited by: Heintzenberg, J. and Charlson, R. J., Strüngmann Forum Reports, 2, Cambridge, MA: The MIT Press, 597, 2009.

Gerber, H., Arends, B. G., and Ackerman, A. S.: New microphysics sensor for aircraft use, Atmos. Res., 31, 235-252, 1994.

Grandey, B. S. and Stier, P.: A critical look at spatial scale choices in satellite-based aerosol indirect effect studies, Atmos. Chem. Phys. Discuss., 10, 15417-15440, doi:10.5194/acpd-10-154172010, 2010.

Haynes, J. M., L'Ecuyer, T. S., Stephens, G. L., Miller, S. D., Mitrescu, C., Wood, N. B., and Tanelli, S.: Rainfall retrieval over the ocean with spaceborne W-band radar, J. Geophys. Res., 114, D00A22, doi:10.1029/2008JD009973, 2009.

Haywood, J. M., Osborne, S. R., and Abel, S. J.: The effect of overlying absorbing aerosol layers on remote sensing retrievals of cloud effective radius and cloud optical depth, Q. J. R. Meteorol. Soc., 130, 779-800, 2004.

Hersey, S. P., Sorooshian, A., Murphy, S. M., Flagan, R. C., and Seinfeld, J. H.: Aerosol hygroscopicity in the marine atmosphere: a closure study using high-time-resolution, multiple-RH DASHSP and size-resolved C-ToF-AMS data, Atmos. Chem. Phys., 9, 2543-2554, doi:10.5194/acp-9-2543-2009, 2009.

Jiang, H. L., Feingold, G., and Koren, I.: Effect of aerosol on trade cumulus cloud morphology, J. Geophys. Res., 114, D11209, doi:10.1029/2009JD011750, 2009.

Jiang, H. L., Feingold, G., and Sorooshian, A.: Effect of aerosol on the susceptibility and efficiency of precipitation in trade cumulus clouds, J. Atmos. Sci., 67, 3525-3540.

Lebsock, M. D., Stephens, G. L., and Kummerow, C.: Multi-sensor observations of aerosol effects on warm clouds, J. Geophys. Res., 113, D15205, doi:10.1029/2008JD009876, 2008.

Lohmann, U. and Feichter, J.: Global indirect aerosol effects: a review, Atmos. Chem. Phys., 5, 715-737, doi:10.5194/acp-5-7152005, 2005.

Lu, M. -L., Sorooshian, A., Jonsson, H. H., Feingold, G., Flagan, R. C., and Seinfeld, J. H.: Marine stratocumulus aerosol-cloud relationships in the MASE-II experiment: Precipitation susceptibility in eastern Pacific marine stratocumulus, J. Geophys. Res., 114, D24203, doi:10.1029/2009JD012774, 2009.

Masunaga, H., Nakajima, T. Y., Nakajima, T., Kachi, M., Oki, R., and Kuroda, S.: Physical properties of maritime low clouds as retrieved by combined use of Tropical Rainfall Measurement Mission Microwave Imager and Visible/Infrared Scanner: Algorithm, J. Geophys. Res., 107, 4083, doi:10.1029/2001JD000743, 2002.

Matsui, T., Masunaga, H., Pielke Sr., R. A., and Tao, W.-K.: Impact of aerosols and atmospheric thermodynamics on cloud properties within the climate system, Geophys. Res. Lett., 31, L06109, doi:10.1029/2003GL019287, 2004. 
Matsui, T., Masunaga, H., Kreidenweis, S. M., Pielke Sr., R. A., Tao, W.-K., Chin, M., and Kaufman, Y. J.: Satellite-based assessment of marine low cloud variability associated with aerosol, atmospheric stability, and the diurnal cycle, J. Geophys. Res., 111, D17204, doi:10.1029/2005JD006097, 2006.

McComiskey, A. and Feingold, G.: Quantifying error in the radiative forcing of the first aerosol indirect effect, Geophys. Res. Lett., 35, L02810, doi:10.1029/2007GL032667, 2008.

McComiskey, A., Feingold, G., Frisch, A. S., Turner, D. D., Miller, M. A., Chiu, J. C., Min, Q., and Ogren, J. A.: An assessment of aerosol-cloud interactions in marine stratus clouds based on surface remote sensing, J. Geophys. Res., 114, D09203, doi:10.1029/2008JD011006, 2009.

Nakajima, T., Higurashi, A., Kawamoto, K., and Penner, J. E.: A possible correlation between satellite-derived cloud and aerosol microphysical parameters, Geophys. Res. Lett., 28, 1171-1174, doi:10.1029/2000GL012186, 2001.

Partain, P.: Cloudsat ECMWF-AUX auxiliary data process description and interface control document, http://www.cloudsat.cira.colostate.edu/dataICDlist.php?go= list $\{\backslash \&\}$ path=/ECMWF-AUX, 2007.

Pawlowska, H. and Brenguier, J. L.: An observational study of drizzle formation in stratocumulus clouds for general circulation model (GCM) parameterizations, J. Geophys. Res., 108(D15), 8630, doi:10.1029/2002JD002679, 2003.

Platnick, S., King, M. D., Ackerman, S. A., Menzel, W. P., Baum, B. A., Riedi, J. C., and Frey, R. A.: The MODIS cloud products: Algorithms and examples from Terra, IEEE Trans. Geosci. Remote Sens., 41, 459-473, 2003.

Quaas, J., Ming, Y., Menon, S., Takemura, T., Wang, M., Penner, J.E., Gettelman, A., Lohmann, U., Bellouin, N., Boucher, O., Sayer, A. M., Thomas, G. E., McComiskey, A., Feingold, G., Hosse, C., Kristjánsson, J. E., Liu, X., Balkanski, Y., Donner, L. J., Ginoux, P. A., Stier, P., Feichter, J., Sednev, I., Bauer, S. E., Koch, D., Grainger, R. G., Kirkevåg, A., Iversen, T., Seland, Ø., Easter, R., Ghan, S. J., Rasch, P. J., Morrison, H., Lamarque, J.-F., Iacono, M. J., Kinne, S., Schulz, M.: Aerosol indirect effects general circulation model intercomparison and evaluation with satellite data, Atmos. Chem. Phys., 9, 8697-8717, doi:10.5194/acp-9-8697-2009, 2009.

Remer, L. A., Kaufman, Y. J., Tanre, D., Mattoo, S., Chu, D. A., Martins, J. V., Li, R. R., Ichoku, C., Levy, R. C., Kleidman, R. G., Eck, T. F., Vermote, E., and Holben, B. N.: The MODIS aerosol algorithm, products, and validation, J. Atmos. Sci., 62, 947-973, 2005.
Rosenfeld, D. and Gutman, G.: Retrieving microphysical properties near the tops of potential rain clouds by multispectral analysis of AVHRR data, Atmos. Res., 34, 259- 283, 1994.

Sorooshian, A., Feingold, G., Lebsock, M. D., Jiang, H., and Stephens, G.: On the precipitation susceptibility of clouds to aerosol perturbations, Geophys. Res. Lett., 36, L13803, doi:10.1029/2009GL038993, 2009a.

Sorooshian, S., Hsu, K. L., Gao, X., Gupta, H. V., Imam, B., and Braithwaite, D.: Evaluation of PERSIANN system satellitebased estimates of tropical rainfall, Bull. Amer. Meteor. Soc., 81, 2035-2046, 2000.

Sorooshian, A., Padró, L. T., Nenes, A., Feingold, G., McComiskey, A., Hersey, S. P., Gates, H., Jonsson, H. H., Miller, S. D., Stephens, G. L., Flagan, R. C., and Seinfeld, J. H.: On the link between ocean biota emissions, aerosol, and maritime clouds: airborne, ground, and satellite measurements off the coast of California, Global Biogeochem. Cycles, 23, GB4007, doi:10.1029/2009GB003464, 2009b.

Sorooshian, A., Feingold, G., Lebsock, M. D., Jiang, H., and Stephens, G.: Deconstructing the precipitation susceptibility construct: improving methodology for aerosolcloud-precipitation studies, J. Geophys. Res., 115, D17201, doi:10.1029/2009JD013426, 2010.

Stevens, B., Feingold, G., Cotton, W. R., and Walko, R. L.: Elements of the microphysical structure of numerically simulated nonprecipitating stratocumulus, J. Atmos. Sci., 53, 980-1006, 1996.

vanZanten, M. C., Stevens, B., Vali, G., and Lenschow, D. H.: Observations of drizzle in nocturnal marine stratocumulus, J. Atmos. Sci., 62, 88-106, 2005.

Wilcox, E. M., Harshvardhan, and Platnick, S.: Estimate of the impact of absorbing aerosol over cloud on the MODIS retrievals of cloud optical thickness and effective radius using two independent retrievals of liquid water path, J. Geophys. Res., 114, D05210, doi:10.1029/2008JD010589, 2009.

Wood, R.: Drizzle in stratiform boundary layer clouds, Part 1: Vertical and horizontal structure, J. Atmos. Sci., 62, 3011-3033, 2005.

Wood, R., Kubar, T., and Hartmann, D.: Understanding the importance of microphysics and macrophysics for warm rain in marine low clouds: Part II, Heuristic models of rain formation, J. Atmos. Sci., 66, 2973-2990, 2009. 